DOI: https://doi.org/10.35699/2238-037X.2020.19823

\title{
A ContextualizaçÃo PELO TRABAlHo E A POSSibilidade de APRENDIZAGEM DE CONCEITOS CIENTÍFICOS
}

\author{
The contextualization by the work and the possibility of learning scientific \\ concepts
}

RAZUCK, Fernando Barcellos ${ }^{1}$

RAZUCK, Renata Cardoso de Sá Ribeiro²

\begin{abstract}
RESUMO
Este trabalho enfatiza a importância da relação entre a educação pelo trabalho e a contextualização no processo de aprendizagem de conceitos científicos. Tem como princípio selecionar estratégias que facilitem a interação dos conceitos químicos com o cotidiano dos alunos, enfocando os aspectos sociais e econômicos pertinentes à sua realidade. Este trabalho foi desenvolvido em uma escola pública de uma cidade-satélite do Distrito Federal, com alunos da modalidade de Educação de Jovens e Adultos (EJA). Inicialmente, os alunos do $1^{\circ}$ Ano do Ensino Médio preencheram um questionário referente às aulas de Química. Os resultados iniciais sugerem uma falta de contextualização na abordagem dos conteúdos, o que se reflete em um baixo interesse pela disciplina. Após a realização de atividades práticas (oficinas), os alunos foram submetidos a um novo questionário. A partir da contextualização com aspectos relacionados à realidade do aluno, verificou-se uma significativa mudança com relação à aprendizagem dos conceitos científicos e ao interesse demonstrado em sala de aula.
\end{abstract}

Palavras-chave: Contextualização pelo trabalho. Educação de Jovens e Adultos. Ensino de Química.

\section{Abstract}

This paper emphasizes the importance of the relation between education and the work context in the process of learning scientific concepts. It has as principle select strategies that facilitate the interaction between the chemical concepts to the daily life of students, focusing on the social and economic aspects relevant to their reality. This study was conducted in a public school in a satellite town of the Federal District, with students from Youth and Adult Education. Initially, students in the 1st year of high school completed a questionnaire referring to chemistry classes. The initial results suggest a lack of context in the approach to the contents, which is reflected in a low interest in the discipline. After carrying out practical activities, students were submitted to a new questionnaire. From the contextualization with aspects related to the student's reality, there was a significant change regarding the learning of scientific concepts and the interest shown in the classroom.

Keywords: Contextualization by the work. Youth and Adult Education. Chemistry Teaching.

\footnotetext{
${ }^{1}$ Doutor em Educação pela Universidade de Brasília. Professor de Química da Secretaria de Educação do Distrito Federal e Analista em Ciência e Tecnologia do Instituto de Radioproteção e Dosimetria. E-mail: razuckdabrasilia@hotmail.com.

2 Doutora em Educação pela Universidade de Brasília. Professora Adjunta da Faculdade de Educação da Universidade Federal do Rio de Janeiro. E-mail: razuckrenata@gmail.com.
}

Trabalho \& Educação | v.29 | n.2 | p.121-132 | maio-ago. | 2020 


\section{INTRODUÇÃO}

De acordo com Silva et al. (2008), com relação ao ensino de Química nas escolas, a grande maioria dos alunos não gostam desta disciplina devido ao fato de que o seu ensino está mais voltado para a retenção de informações passivas - com o objetivo de serem memorizadas para imediata aplicação em provas- correspondendo assim ao chamado modelo de transmissão/recepção, vinculado mais ao modelo tradicional de ensino do que para um perfil mais participativo do aluno, no qual este tem um papel central no processo de ensino-aprendizagem.

Ainda segundo os autores, como uma tentativa de se melhorar a aprendizagem dessa disciplina, pode-se vislumbrar o trabalho como eixo articulador entre a escola e a realidade dos alunos, por meio da participação destes em oficinas.

Ou seja, oficinas aplicáveis ao cotidiano social dos alunos acabariam por abordar diversos assuntos referentes ao conteúdo, não só de Química, como também de várias outras disciplinas da grade curricular (por exemplo, Física, Biologia, Matemática, Geografia, História, Filosofia e Sociologia), o que, automaticamente, remeteria a uma visão mais interdisciplinar do ensino (RAZUCK; RAZUCK, 2010a; RAZUCK; RAZUCK, 2010b).

Dessa maneira, a fim de que o aluno tenha um aprendizado satisfatório, entende-se que é preciso utilizar objetos e acontecimentos do seu dia a dia como ferramentas para uma melhor compreensão dos conteúdos ministrados em aula (SANTOS; MORTIMER, 2002). Ou seja, o conteúdo apresentado deve estar inserido no cotidiano do aluno, contextualizando ${ }^{3}$ o conhecimento científico com a sua realidade social.

Assim, um dos principais objetivos da contextualização é a formação de cidadãos críticos. A contextualização e a interdisciplinaridade acabam por favorecer um ensino de qualidade, além de elevar a autoestima dos educandos (SANTOS; MORTIMER, 2002).

Logo, segundo Santos e Mortimer (2002), a formação de alunos críticos está diretamente relacionada ao seu processo de escolarização. Para os autores, a leitura, elaboração de suposições, a interpretação e a clareza de expressão são algumas das habilidades que podem ser desenvolvidas neste processo.

\section{O JOVEM E O MUNDO DO TRABALHO}

Pode-se dizer que a atual forma de organização do trabalho na sociedade, com a crescente industrialização, o estilo de vida, a incorporação da mulher no mercado de trabalho e as dificuldades cada vez maiores para a ascensão profissional traz repercussões psicológicas inquestionáveis aos jovens (LIMA, 2004).

Além disso, ao analisar a estrutura educacional brasileira, Lima (2004) nota que o sistema educativo atual não prepara o aluno para o mundo do trabalho, já que praticamente nenhuma correlação é feita com as questões profissionais.

Por outro lado, analisando a questão familiar, o autor observa que os filhos (alunos) crescem distantes da realidade profissional de seus pais, fato este que não era comum

\footnotetext{
${ }^{3}$ De acordo com Santos e Mortimer (2002), deve-se ficar atento para não se confundir contextualização com a exemplificação. No caso, a exemplificação é uma breve correlação entre o conteúdo trabalhado em sala de aula e o cotidiano do aluno. Já a contextualização é o processo inverso: a partir do cotidiano do aluno chega-se a exploração dos conceitos Químicos pertinentes a esse. Neste último caso, a abordagem é mais profunda e significativa.
} 
há algumas décadas, nas quais as crianças cresciam no convívio com o trabalho, inclusive aprendendo os ofícios de seus pais e familiares.

Consequentemente, sabe-se que ao concluir o Ensino Médio, e muitas vezes antes mesmo de terminá-lo, esses alunos se deparam em um delicado momento: o que fazer após a sua conclusão?

Isso porque no período entre o meio e o final da adolescência os jovens são levados a se preocupar com sua entrada no mundo do trabalho (fenômeno esse que não é privativo de época ou cultura), de forma que as expectativas sociais em torno deles são claramente dependentes com relação a fatores históricos, culturais e sociais (LIMA, 2004).

\section{FundamentAÇÃo TEÓRICA}

Sobre a análise da educação pelo trabalho, para Vygotsky (2003), a falta de correlação com o mundo do trabalho gera jovens sem perspectivas futuras com relação à vida profissional, e isto os leva ao desinteresse e a falta de estímulo na escola.

Para o autor, é importante que o trabalho seja a própria base do processo educativo, onde neste caso, "o trabalho não se incorpora como tema de ensino nem como método ou meio de ensino, mas como matéria-prima da educação" (VYGOTSKY, 2003, p. 182).

Além disso, afirma Vygotsky (2003, p. 81), "não só se introduz o trabalho na escola, mas também a escola no trabalho".

Para Vygotsky (2003), na educação pelo trabalho, aprende-se que este é um processo comum entre os seres e que requer a coordenação dos esforços e a regulação das próprias reações para o melhor convívio coletivo.

No trabalho, aprende-se simultaneamente a subordinação e a dominação, excluindo-se os aspectos negativos de ambos. É nesse sentido que o autor vê o trabalho com pleno de significado psicológico.

Vygotsky (2003) lembra ainda que as ciências naturais foram tradicionalmente inseridas na grade curricular apenas no início do século XX e essas disciplinas enfrentam uma forte oposição educacional, o que contribui para a dificuldade existente em seu processo de ensino-aprendizagem.

O autor observa então que as escolas dividem seus planos de estudos em dois grandes grupos inconciliáveis: as ciências naturais (ciências da natureza) e as ciências humanas (ciências do espírito). Desta forma, entre ambas não existe nenhuma ponte no âmbito escolar.

Segundo Vygotsky (2003), os alunos são educados e instruídos com a convicção, talvez inconsciente, de que na realidade também existem dois mundos diferentes: o da natureza e o do ser humano, e que ambos estão separados por um abismo intransponível.

A escola parece servir para enraizar e aumentar essa bifurcação do conhecimento e da experiência. Além disso, na escola, o saber é assimilado como algo pronto e acabado, no qual a própria busca do conhecimento é esquecida. O conhecimento não deveria ser algo terminado, mas um processo contínuo de criatividade e luta da humanidade pelo domínio da natureza (VYGOTSKY, 2003). 
Então, se é o trabalho que constitui a natureza humana, e se a formação do homem está centrada no trabalho, isto é, no processo pelo qual o homem produz a sua existência, é também o trabalho que define a existência histórica dos homens.

Por meio do trabalho o homem vai produzindo as condições de sua existência, e vai transformando a natureza e criando, portanto, a cultura, criando um mundo humano. Deste modo, a realidade da escola tem que ser vista nesse quadro. A escola não pode ser algo restrito, mas sim deve estimular o desenvolvimento de habilidades.

Já para Saviani (1989), à medida que o processo escolar se desenvolve, coloca-se a exigência de que estas relações e, portanto, os mecanismos que caracterizam o processo do trabalho, sejam explicitados.

Nesse sentido, o autor entende que o Ensino Médio deveria se organizar na forma de uma explicitação da questão do trabalho. Nessa etapa, o trabalho já deveria aparecer não apenas como um pressuposto, mas também como a maneira que a escola se organiza.

Trata-se de explicitar o modo como o trabalho se desenvolve e está organizado na sociedade moderna, abarcando a questão da Politecnia. Organizar o Ensino Médio sobre a base da Politecnia não significa multiplicar as habilitações ao infinito para se cobrir todas as formas de atividade social. Ou seja, propicia a realização do trabalho real, por meio da articulação entre o trabalho manual e o intelectual.

\section{O PAPEL dA ESCOLA E A ARTICULAÇÃO COM O MUNDO DO TRABALHO}

Dessa forma, para Gonçalves (2004), a escola tem um importante papel social na interação com a comunidade: a formação de cidadãos críticos. Há, entretanto, segundo o autor, dificuldades de se trabalhar com assuntos do currículo direcionados com o cotidiano do aluno, devido à vários fatores, entre os quais por exemplo: a falta de capacitação do educando (uma grande parte dos educadores tem dificuldade de contextualizar os assuntos possivelmente devido a sua formação acadêmica, que não visa esse tipo de abordagem), a falta de estrutura da escola ou até mesmo a falta de material escolar.

Nesse sentido, conforme Teixeira (2003), a educação escolar deve ter como uns dos principais objetivos preparar o educando para cidadania. Destaca como exemplo neste sentido o movimento Ciência, Tecnologia e Sociedade (CTS), o qual está atrelado à pedagogia histórico-crítica.

Para o autor, essas duas correntes trazem ideias interessantes que contribuem de forma significativa na reflexão sobre o processo da educação. Isto porque vincula o conhecimento científico à realidade do aluno, além de sugerir a contextualização dos conteúdos para emancipação das classes excluídas da sociedade atual.

Isso porque, de acordo com Santos et al. (2005), a escolha de um tema gerador dentro do conteúdo programático já é o começo para chegar à contextualização, e a partir daí deve-se seguir a elaboração de uma situação-problema.

Portanto, é interessante que especificamente para a disciplina Química ela perpasse por esses dois passos, o que não seria tarefa difícil, uma vez que a Química está presente em tudo. 
Para isso, entretanto, segundo Peixoto (2004), quando determinado assunto de Química for abordado e relacionado com o cotidiano, o professor tem que ter domínio do mesmo, pois, se o conhecimento por parte do educador for superficial o trabalho a ser realizado será pobre e fragmentado.

Ou seja, qualquer abordagem deve ser sustentada por um conhecimento estruturado e seguro. Não basta, portanto, escolher exemplos dos quais, muitas vezes, os alunos possuem pouco conhecimento, o que leva a trabalhar os conteúdos da Química de uma forma superficial.

Assim, para Peixoto (2004), é de extrema relevância a utilização de temas geradores sobre assuntos do cotidiano, nos quais o conhecimento científico seja capaz de atender às muitas dúvidas que possam surgir pelos alunos.

Desta forma, a relação do cotidiano com as atividades de ensino deve seguir uma sequência lógica, para não correr o risco de trabalhar com temas aleatórios e fazer com que o aluno não alcance um aprendizado significativo e duradouro. Caso contrário, a contextualização terminaria como uma simples memorização.

Especificamente com relação ao Ensino de Jovens e Adultos (EJA), atividades que abordem o cotidiano dos alunos, seja como parte do conteúdo programático, seja na forma de oficinas temáticas, auxiliam no aprendizado com relação às disciplinas, sejam elas das ciências exatas, humanas, da linguagem ou sociais (RAZUCK; RAZUCK, 2012; RAZUCK; RAZUCK, 2017).

Ainda sobre o papel da escola como instituição formadora para o trabalho, é fundamental a clareza de que esse papel não é mais só da escola, diante das imensas transformações no mundo do trabalho. Há ainda um abismo entre o que se ensina e o que se pede aos alunos quando conseguem finalmente se inserir no mercado de trabalho.

O trabalho tem, portanto, que ser uma intenção ontologicamente voltada para o processo de humanização do homem em seu sentido amplo. Até mesmo os níveis considerados mais avançados de sociabilidade, como a práxis política, a religião, a ética, a filosofia, a arte e etc., encontram sua origem a partir do trabalho, do intercâmbio metabólico entre ser social e a natureza.

Para Antunes (2003), tem-se, portanto, por meio do trabalho, um processo que simultaneamente altera a natureza e autotransforma o próprio ser que trabalha. A natureza humana é, então, metamorfoseada a partir do processo de realização do trabalho, dada a existência de uma proposição teleológica e de uma realização prática.

Defende-se aqui então a ideia da melhoria do sistema educacional a partir da articulação com o trabalho, pois se acredita que assim se estará despertando o interesse dos alunos (já que o trabalho é uma realidade social).

Além disso, entende-se que esta articulação colabora para uma melhor integração social. Acredita-se que a partir da articulação com o trabalho é possível despertar o interesse dos nossos alunos para a sua realidade social.

Nesta concepção de trabalho, Frigotto (2005) afirma que o mesmo se constitui em direito e dever, e engendra um princípio formativo ou educativo, uma vez que deriva do fato de que todos os seres humanos são seres da natureza que têm necessidades básicas, como de se alimentar, proteger e criar seus meios de vida. 
Portanto, para o autor, é fundamental socializar o princípio de que a tarefa de prover a subsistência pelo trabalho é comum a todos os seres humanos, evitando-se, desta forma, a criação de indivíduos ou grupos que explorem e vivam à custa do trabalho de outros.

Sobre a importância do trabalho como princípio educativo, entende-se que:

O trabalho como princípio educativo, então, não é, primeiro e sobretudo, uma técnica didática ou metodológica no processo de aprendizagem, mas um princípio ético-político. Dentro desta perspectiva o trabalho é, ao mesmo tempo, um dever e um direito. Dever por ser justo que todos colaborem na produção dos bens materiais, culturais e simbólicos, fundamentais à produção da vida humana. Um direito por ser o ser humano um ser da natureza que necessita estabelecer, por sua ação consciente, um metabolismo com o meio natural transformando em bens para sua produção e reprodução (FRIGOTTO, 2005, p. 3).

\section{A IMPORTÂNCIA DA EXPERIMENTAÇÃO NO ENSINO DE QUÍMICA}

Vale destacar ainda a importância da experimentação no ensino da Química. Nesse sentido, Ribeiro et al. (2004) discorre sobre a importância de usar os experimentos em sala de aula com a finalidade de abordar conceitos fundamentais de ciências. Para a autora, o experimento é uma maneira alternativa de se introduzir determinado assunto a ser estudado.

Desta maneira, conceitos alternativos são resgatados através de situações simples e várias dúvidas posteriormente serão elucidadas em relação ao assunto trabalhado, e a partir daí surge uma educação com uma aprendizagem mais "significativa".

Segundo Ribeiro et al.(2004) este é um forte aspecto da visão construtivista do conhecimento, na qual a primeira tarefa para qualquer professor é investigar as ideias e expectativas sobre o tópico que os alunos vão estudar na aula.

Em geral, a utilização dos experimentos para este fim é feita através da entrega de roteiros ou guias de prática e posterior aplicação de questionários. Ribeiro et al. (2004) sugere que questões formuladas pelo próprio aluno estimularão melhor a sua compreensão do que questões formuladas pelos professores.

No entanto, a depender do objetivo do trabalho a ser desenvolvido, a elaboração do questionário por parte do professor torna-se indispensável.

Vera (1999) sugere que os educadores não se limitem em fazer simples experimentos, como por exemplo, plantar feijão no algodão molhado. As experiências de ciências têm que estar associadas ao cotidiano dos alunos, citando como exemplo o trabalho de alguns professores de uma escola de São Paulo, que vem fazendo atividades práticas bem próximas da realidade dos educandos, tais quais: fabricação de xampu, sabonetes, perfume e outros, tudo isso dentro da escola, seja no laboratório, seja na sala de aula.

Observa-se que com isso, ao serem realizadas atividades práticas (oficinas) na escola, utilizando, preferencialmente, materiais encontrados no seu cotidiano, os alunos possam com maior facilidade relacionar os conceitos científicos trabalhados em sala de aula com a sua realidade social.

Diante dessas características com relação ao processo educativo, mais especificamente com relação ao Ensino Médio, o objetivo deste trabalho é o de estimular o surgimento de novos interesses por parte do aluno, com relação à Química, criando condições 
necessárias para o enfrentamento de diversas situações cotidianas que envolvam temas abordados pela disciplina.

Este tema foi escolhido com o intuito de se modificar a situação de desinteresse demonstrada por alunos com relação a conteúdos ministrados na disciplina Química, a partir da observação em salas de aula de uma escola pública do Distrito Federal, na modalidade de ensino EJA (Educação de Jovens e Adultos).

Para tal, partiu-se da necessidade de superação do ensino puramente conteudista, o qual não tem relação com a vida cotidiana dos discentes, para uma abordagem relacionada com a realidade dos alunos.

\section{Metodologia}

Tendo em vista o que foi abordado anteriormente neste trabalho, com os objetivos do ensino pelo enfoque do trabalho, estas ideias, neste artigo, convergiram em estratégias que facilitassem a relação dos conceitos químicos com o cotidiano dos alunos do $1^{\circ}$ ano da Educação de Jovens e Adultos (EJA) de uma Escola Pública do Distrito Federal, visando o desenvolvimento da percepção da Química nas suas vidas e sua influência nos aspectos social e econômico.

Além disso, buscou-se o reconhecimento de que a falta de contextualização dos conteúdos pode interferir no baixo rendimento escolar do educando.

Por se tratar da modalidade de ensino EJA, cujo período letivo é de apenas um (1) semestre (no caso, cada semestre letivo é considerado como um ano letivo), com aulas no período noturno, as atividades práticas foram realizadas no laboratório de Ciências ou de forma demonstrativa em sala de aula, uma vez por semana - de forma que, devido à carga horária de 2horas-aula semanais, uma aula era destinada às atividades práticas/demonstrativas e a outra para a abordagem teórica em sala de aula.

Estas atividades foram realizadas nos dois (2) semestres correspondentes ao ano letivo, ou seja, dois semestres diferentes. Participaram das atividades no total 88 alunos, sendo a sua maioria (52) composta por alunas. A faixa etária variou dos 19 até os 67 anos.

Cada atividade prática envolvia discussões sobre a realidade social do aluno, leitura de textos que abordassem de que maneira a Química poderia ajudar na participação social de cada um e debates de questões Físicas e Químicas, como mudanças de estado físico, origem e estrutura dos materiais.

A coleta de dados foi feita por meio de questionário no primeiro encontro e após o correspondente a oito (8) aulas (quatro semanas depois, pois a carga horária de Química é de 2 horas/aula semanais).

Assim, buscou se uma visão de como as aulas estão sendo ministradas e se realmente está ocorrendo à contextualização dos conceitos químicos. O questionário tinha as seguintes perguntas:

1) Você gosta de estudar Química? Por quê?

2) Qual o conteúdo de Química que mais chamou a sua atenção no ano? Justifique.

3) Quais aulas despertaram mais o seu interesse? Práticas ou Teóricas?

4) Você acha importante a disciplina Química para o seu dia-a-dia? Por quê? 
5) Você trabalha ou estagia no turno oposto? Seu trabalho é informal?

6) Qual fato do seu cotidiano que está relacionado com o conhecimento de Química?

7) Durante o período de ensino, que disciplina relacionou o seu conteúdo com o cotidiano? De que maneira foi feita essa relação?

Após as aulas iniciais, sugeriu-se aos alunos algumas práticas diretamente relacionadas ao mundo do trabalho, ou seja, aplicáveis ao cotidiano. Tais práticas foram: produção de perfumes, velas artesanais e materiais de limpeza.

Logo após a realização das práticas, uma nova rodada de perguntas foi feita novamente aos alunos, sendo elas:

1) O que acharam das práticas?

2) O que fizeram nas práticas?

3) Qual prática mais gostaram?

4) Vocês pretendem fazer isso em casa?

5) Quais disciplinas vocês conseguiram identificar durante as práticas?

6) Vocês gostam de Química?

7) Quais disciplinas estão relacionadas com o seu cotidiano?

\section{Resultados}

Ao analisar as respostas do questionário aplicado antes da realização das aulas práticas, observou-se que a grande maioria dos alunos disse não gostar de estudar Química.

Associavam a disciplina a algo que deveria ser mecânico e não viam correlação com seu cotidiano (os conteúdos de Química estudados na 1a série foram fenômenos naturais químicos, físicos e biológicos, classificação de substâncias e separação de misturas).

Para eles, o conteúdo apresentado tinha pouca relação com o seu dia-a-dia, pois os conceitos apresentados em sala de aula eram pouco contextualizados.

Por exemplo, de acordo com a aluna N., de 56 anos, as aulas de Química eram muito distantes da sua realidade: "Pra mim que estou muito tempo sem estudar,dá até medo! É muita fórmula, muita conta, tem hora que fala de Física, tem hora que fala de Química. Fica muito difícil!'.

Já para o aluno P. de 19 anos, que acabara de vir do Ensino Médio Regular, foram exatamente as disciplinas das ciências exatas, como a própria Química, além da Física e da Matemática, que o afastaram da escola: "Sabe professor, não é nem porque eu gosto mais de Artes e Filosofia não, é porque é chato e difícil. Além disso, tem que se dedicar mais, pois sem fazer exercícios não tem a menor chance. Já as outras matérias, sabendo discutir, você passa de ano".

Além disso, praticamente $70 \%$ dos alunos da turma realizavam alguma atividade remunerada, sendo que apenas $14 \%$ tinham um trabalho formal, o que demonstra a inserção informal no mundo do trabalho, principalmente na área do comércio. Após a prática, muitos alunos demonstraram interesse em tentar continuar os estudos no nível superior. 
Com relação às práticas (produção de perfumes, velas artesanais e materiais de limpeza),cerca de 52\% afirmaram ter se interessado mais desta dinâmica, principalmente daquela que envolvia a fabricação de velas artesanais, por se tratar de algo mais fácil ou acessível. Muitos, inclusive, afirmaram ter a intenção de reproduzir esta prática em casa.

Desta forma, com relação ao segundo questionário, a visão dos alunos sobre a Química mudou significativamente, sendo que $85 \%$ dos alunos responderam gostar da disciplina.

Para a aluna N. de 56 anos, que a princípio havia dito ter medo da Química, enxergou nas práticas algo que já fazia no seu cotidiano: "Pior professor que tem coisa aí que eu já sabia fazer, mas que eu nem sabia que era Química ou Ciência. As vezes parece que muita coisa que a gente faz é ciência, só que a gente faz de um jeito diferente."

Os alunos também disseram que um dos fatores que despertou interesse com relação às práticas foi a questão da contextualização, pois assim conseguiram identificar os conceitos estudados em sala de aula com o seu cotidiano. Afirmaram também que esta abordagem acaba por aproximar a disciplina da sua realidade.

Para o aluno P. de 19 anos, oriundo do ensino regular, a forma com que o EJA aborda os conteúdos parece ser mais integrada: "Não sei se é de propósito, mas quando o senhor fala de uma matéria, a professora de Biologia e de Física falaram de coisas parecidas. Por exemplo, na aula de estados físicos, o professor de Física falou da mesma coisa, só que de outra maneira, bem parecida. E aí algumas palavras que vocês usaram, quando a professora de Biologia usou, eu já sabia!'.

No geral, as disciplinas citadas após a realização das práticas pelos alunos com as quais conseguiram relacionar com o seu cotidiano foram, nesta ordem: Química e Matemática, em seguida, Português, Biologia e Física e por último, Geografia e História.

No caso das disciplinas mais citadas que conseguiram relacionar o conteúdo com o seu cotidiano foram a própria Química (uma vez que as práticas abordavam a ciência em si), Física (devido as questões que envolviam mudança de estado físico), Matemática (com relação aos cálculos fundamentais no comércio, além dos próprios cálculos estequiométricos que envolviam quantidade e proporcionalidade) e Português (devido ao seu uso cotidiano).

\section{CONSIDERAÇÕES FINAIS}

No geral, os alunos sem perspectivas para o mercado de trabalho se questionam quanto à necessidade de estudar certos conteúdos na disciplina de Química e se isto facilitará a compreensão dos fatos ocorridos na sua vida cotidiana ou na sua futura profissão. Portanto, faz-se necessário criar alternativas que possibilitem a inclusão social destes jovens.

Observa-se, além disso, que o trabalho informal está em ascensão em todo país, o eu propicia aos jovens a produção de materiais de consumo na sua residência de baixo custo, como produtos de limpeza, sabonetes, velas artesanais e perfumes.

Isto acaba por demonstrar o surgimento de um perfil mais autônomo dos estudantes, uma vez que começam a aproximar o conhecimento científico do seu meio social, levando a escolher de que forma este conhecimento pode agora ser contextualizado. 
A venda destes produtos também acaba por ajudá-los financeiramente, desenvolvendo desta maneira estratégias para a inclusão social dos jovens, uma vez que aproxima esta atividade às necessidades da sua comunidade.

Refletindo nesta situação enfrentada pelos estudantes, é necessário se fazer a contextualização dos conteúdos considerando os materiais produzidos pelos jovens fora da sala de aula.

Na tentativa de uma "aprendizagem mais significativa" e a partir do enfoque direcionado no referencial teórico, resolveu-se então trabalhar atividades educacionais que estivessem relacionadas com a questão do trabalho, com o intuito de despertar 0 interesse do aluno.

Durante a realização das práticas, pode-se observar como o envolvimento com a realidade do trabalho intercedeu de forma a despertar o interesse dos alunos. Os alunos tornaram-se curiosos (pois passaram a fazer questionamentos até mesmo durante as aulas, buscavam explicações não só para as questões relacionadas com a Química, mas também sobre outros fatos intrigantes) e dedicados (pois passaram a ser pontuais - mesmo nas atividades desenvolvidas em horário extraclasse - e passaram a apresentar tarefas com mais frequência).

Obviamente, os alunos questionadores exigem muito mais de seus professores, mas após a experiência de trabalho com alunos interessados, conclui-se que a aula em si se torna muito mais interessante e desafiadora para todas as partes envolvidas.

Além disso, nesta nova linha de abordagem, é necessário que os docentes estejam interessados e dedicados. É importante que os educadores tenham um bom aprofundamento nos conteúdos específicos, além de constante atualização.

Portanto, para que haja mudanças significativas no sistema educacional, também é preciso que os professores assumam um grande compromisso: a procura de capacitação e principalmente à vontade de mudar, sair do comodismo, passar a ser um educador pesquisador, sempre em busca de novidades e metodologias inovadoras, tendo como finalidade à formação de pessoas críticas e transformadoras do meio em que vivem.

O aspecto principal a ser considerado no processo educativo para que haja uma prática mais eficaz na transformação da sociedade é a própria emancipação do docente que, às vezes, apresenta uma visão elementar e não tem nenhum compromisso político na construção de um cidadão crítico e atuante.

Algumas vezes o professor prefere reproduzir o sistema educacional conservador e atividades totalmente neutras da realidade. Além disso, as estruturas sociais e escolares acabam organizando sempre o modelo de sistema que não beneficiam as classes excluídas.

Porém, para que isto aconteça, é necessário que o Estado elabore Políticas Públicas com a finalidade de preparar este professor a desenvolver um perfil pesquisador, de forma com que venha a refletir não só sobre os seus conhecimentos didáticos, mas principalmente sobre a realidade que o circunda e ao seu meio escolar.

Para que seja efetivamente possível fazer críticas ao método docente, é necessário, primeiramente, fazer com que os recursos financeiros cheguem à escola, a fim de que todo o ambiente escolar propicie ferramentas didáticas para a construção de uma visão crítica da sociedade. 
Por fim, acredita-se que este trabalho leva a uma reflexão sobre a educação, o trabalho e a contextualização por parte do professor de assuntos que envolvam o dia-a-dia dos seus alunos.

No caso específico, por se tratar do ensino de Jovens e Adultos, apesar da suposição de que eles já se encontram inseridos no mercado de trabalho, tendo em vista o fator etário, observa-se que, na verdade, ainda existe uma grande carência de saber com relação aos conceitos científicos, bem como uma imagem negativa e baixa estima, uma vez que se consideram aleijados do processo educativo e econômico.

Entende-se assim que uma abordagem na qual se envolva a questão do trabalho, como a proposta CTS, que remete às reflexões histórico-culturais, acaba por trazer o aluno de volta à discussões não só do seu interesse, mas também da sua importância no processo social.

Portanto, o que facilita a realização de trabalhos desse tipo é a curiosidade das pessoas em saber a composição de certos materiais, como no caso citado anteriormente dos cosméticos. Após a fabricação dos mesmos, os alunos utilizaram o computador para digitação dos textos que serão empregados nos rótulos.

Nesta etapa, houve o envolvimento das disciplinas de Informática e Português, ou seja, ocorreu a multidisciplinaridade. Os alunos ganharam muito com a experiência. Aprenderam a usar instrumentos de laboratório, conheceram propriedades de algumas substâncias e observaram reações químicas.

\section{REFERÊNCIAS}

ANTUNES, R. Os sentidos do trabalho: ensaio sobre a afirmação e a negação do trabalho. Boitempo: São Paulo, 2003.

SILVA, R. R. da; RAZUCK, R. C. S. R.; TUNES, E. Desafios da escola atual: a educação pelo trabalho. Química Nova, v. 31, n. 2, 452-461, 2008.

FRIGOTTO, G. Concepções e mudanças no mundo do trabalho e o ensino médio. In: FRIGOTTO, G.; CIAVATTA, M.; RAMOS, M. (Org.). Ensino Médio Integrado: Concepção e contradição. 1 ed. São Paulo: Cortez, 2005.

GONÇALVES, T. V. O. Educação em Ciências e Comunidade: Investigando a construção de saberes em ensaios de professores na Amazônia brasileira, acerca de uma prática docente diferenciada. Revista Brasileira de Pesquisa em Educação em Ciências, Porto Alegre, v. 4, n. 2, p. 53-62, 2004. Disponível em: http://www.fc.unesp.br/abrapec/revistav4n2.htm. Acesso em: 13 mar. 2019.

LIMA, M. R. O solo no ensino de ciências no nível Fundamental. Ciência e Educação (UNESP), Bauru (SP), v. 11, n. 3, p. 191-212, 2005. Disponível em: http:/www.fc.unesp.br/pos/revista/vol11num3.htm. Acesso em: 14 jan. 2019.

LIMA, N. T. Juventude e o ensino médio: de costas para o futuro? Ensino Médio: ciência, cultura e trabalho. Brasília, MEC, SEMTEC, 2004.

PEIXOTO, Décio Pinheiro. Ensino de Química e Cotidiano. 2004. Disponível em: http://www.moderna.com.br/moderna/didaticos/em/artigos/2004/0031.htm. Acesso em: 13 maio 2019.

RAZUCK, F.B.; RAZUCK, R. C. S. R. Gripe A: a escola no processo informativo. Revista de Ensino de Biologia da Associação Brasileira de Ensino de Biologia (SBEnBio), v. 3, p. 3615-3623, 2010a.

RAZUCK, F.B.; RAZUCK, R. C. S. R. Saúde escolar: a discussão da obesidade na escola. Revista de Ensino de Biologia da Associação Brasileira de Ensino de Biologia (SBEnBio), v. 3, p. 281-290, 2010b. 
RAZUCK, F.B.; RAZUCK, R. C. S. R. O combate ao tabaco na escola - a interferência da indústria tabagista. Revista de Ensino de Biologia da Associação Brasileira de Ensino de Biologia (SBEnBio), v. 5, p. 112, 2012.

RAZUCK, F.B.; RAZUCK, R. C. S. R. As Armas não Letais como Abordagem temática para o Ensino de Química. Ensenanza de Las Ciencias, v. Extra, p. 1159-1164, 2017.

RIBEIRO, E. M. G.; PINTO, N. M. A.; BARBOSA, R. M. N. Papel da experimentação em sala de aula com diferentes abordagens. 2004. Disponível em: http://www.moderna.com.br/moderna/didaticos/emlartigos/2004/0037.htm. Acesso em: 12 maio 2019.

SANTOS, V. T.; ALMEIDA, M. Â. V. de; CAMPOS, Â. F. Concepções de professores de química do ensino médio sobre a resolução de situações-problema. Ensaio. Pesquisa em Educação em Ciências, v. 7, n. 1, p. 1-12, 2005. Disponível em: http://www.fc.unesp.br/abrapec/revistav5n3.htm. Acesso em: 13 jan. 2019.

SANTOS, W. L. P.; MORTIMER, E. F. Uma Análise de Pressupostos Teóricos da Abordagem C-T-S (Ciência-Tecnologia-Sociedade) no Contexto da Educação Brasileira. Ensaio. Pesquisa em Educação em Ciências, Belo Horizonte, v. 2, n. 2, p. 133-162, 2002.

SAVIANI, D. Sobre a Concepção de Politecnia. 1. ed. Rio de Janeiro: Fundação Oswaldo Cruz, v. 1. 50 p., 1989.

TEIXEIRA, P. M. A educação científica sob a perspectiva da pedagogia histórico-crítica e do movimento C.T.S. no ensino de ciências. Revista Brasileira de Pesquisa em Educação em Ciências, ABRAPEC: Porto Alegre, v. 3 (1), n. 1, p. 88-102, 2003. Disponível em: http://www.fc.unesp.br/pos/revista/vol9num2.htm. Acesso em: 14 jan. 2019.

VERA, A. Jovens Alquimistas. 1999. Disponível em: http://novaescola.abril.com.br/ed/127_nov99$/ \mathrm{htm} /$ ciencias.htm. Acesso em: 12 maio 2019.

VIGOTSKI, L. S. Psicologia Pedagógica. Porto Alegre: Artmed, 2003.

Data da submissão: 26/03/2020

Data da aprovação: 04/09/2020 